\title{
Analisis Metode Elemen Hingga Artificial Hip Joint Saat Gerakan Salat
}

\author{
Aditya Candratama*, Yogi Prasetyo, Jamari, Rifky Ismail, Ismoyo Haryanto \\ Departemen Teknik Mesin, Fakultas Teknik, Universitas Diponegoro \\ Jl. Prof. H. Soedarto, SH, Tembalang-Semarang 50275, Telp. +62247460059 \\ *E-mail: adityacandratama@gmail.com
}

\begin{abstract}
The main function of the hip joint is to support the human body in carrying out various activities in daily life. Mechanically the hip joint is a socket and ball joint that connects the fermur head and pelvis acetabulum. In many cases, this hip joint can experience permanent damage caused by calcification, aging or accidents. In such cases the replacement of the hip joint with an artificial hip joint is needed. However, to prevent damage, there are some restrictions in the use of artificial hip joints on several movements, including squatting, running, and salat. This limitation will of course severely limit the daily activities of persons with artificial hip joint replacement. In this study the measurement of the reaction force or ground reaction force $(G R F)$ has been carried out on conditions when an artificial hip joint performs salat movements. This salat movement was chosen because it represented a combination of restricted movements. The results of the GRF measurement are then used as load data in the stress analysis using FEM. The results of the analysis show that the stress that occurs in the movement of salat when standing, ruku' and sujud are $32.15 \mathrm{MPa}$; $32.46 \mathrm{MPa}$ and $21.6 \mathrm{MPa}$ respectively. Whereas the stress when sitting between two sujud is $19.1 \mathrm{MPa}$ for the right foot and 9.3 $\mathrm{MPa}$ for the left foot. The stress at the end of tahiyat is $21.7 \mathrm{MPa}$ for the right foot and $26 \mathrm{MPa}$ for the left foot.
\end{abstract}

Keywords: artificial hip joint, ground reaction force, FEM, stress, deformation

\begin{abstract}
Abstrak
Fungsi utama sendi panggul adalah sebagai penopang tubuh manusia dalam melakukan berbagai aktivitas dalam kehidupan sehari-hari. Secara mekanis sambungan pada sendi panggul (hip joint) merupakan socket and ball joint yang menghubungkan antara fermur head dan pelvis acetabulum. Pada banyak kasus, sendi panggul ini dapat mengalami kerusakaan permanen yang disebabkan oleh pengapuran, penuaan atau kecelakaan. Untuk kasus yang demikian tindakan penggantian sendi panggul dengan sendi panggul buatan (artificial hip joint replacement) sangat diperlukan. Akan tetapi untuk mencegah terjadinya kerusakan maka dalam penggunaan sendi panggul buatan ini diberikan pembatasan pada beberapa gerakan, diantaranya adalah jongkok, berlari, dan salat. Pembatasan ini tentu saja akan sangat membatasi aktivitas keseharian penyandangnya. Oleh karena itu dalam penelitian ini analisis FEM sendi panggul dilakukan untuk menentukan tegangan yang terjadi pada gerakan yang dibatasi tersebut. Hasil analisis ini diperlukan sebagai pertimbangan agar dapat dirancang sendi panggul buatan yang tetap dapat memberikan kebebasan gerak bagi penyandangnya. Dalam penelitian ini pengukuran beban gaya reaksi atau ground reaction force (GRF) telah dilakukan pada kondisi saat penyandang sendi panggul buatan melakukan gerakan-gerakan salat. Gerakan salat ini dipilih karena merepresentasikan kombinasi gerakan-gerakan yang dibatasi. Hasil pengukuran GRF ini selanjutnya digunakan sebagai data beban dalam analisis tegangan menggunakan FEM. Hasil analisis menunjukkan bahswa besar tegangan yang terjadi pada gerakan salat saat berdiri, ruku' dan sujud masing-masing adalah 32,15 MPa; 32,46 MPa dan 21,6 MPa. Sedangkan pada saat duduk diantara dua sujud diperoleh tegangan sebesar 19,1 MPa untuk kaki kanan dan 9,3 MPa untuk kaki kiri. Adapun tegangan pada saat tahiyat akhir adalah 21,7 MPa untuk kaki kanan dan $26 \mathrm{MPa}$ untuk kaki kiri.
\end{abstract}

Kata kunci: Artificial hip joint, Ground reaction force, FEM, Tegangan, Deformasi

\section{Pendahuluan}

Sendi panggul buatan berfungsi sebagai pengganti dari sendi panggul asli ketika mengalami kerusakan karena berbagai macam sebab seperti arthritis, cacat lahir, pertumbuhan abnormal maupun kecelakaan. Sebagai pengganti sendi panggul asli yang berbentuk ball and socket, sendi panggul buatan memiliki bagian-bagian utama, seperti ditunjukkan pada Gambar 1, yaitu: stem, femoral head, acetabullar cup dan acetabullar liner [1]. Material yang digunakan dalam sendi panggul buatan harus memiliki biokompabilitas yang baik. Stem, femoral head dan acetabullar cup umumnya menggunakan material logam seperti Co-Cr-Mo, alumina/zirconia, Ti-6Al-4 V, AISI 316L dan beberapa 
menggunakan keramik. Umumnya acetabullar liner menggunakan UHMWPE karena memiliki biokompabilitas yang baik dan ketahanannya terhadap impact [2].

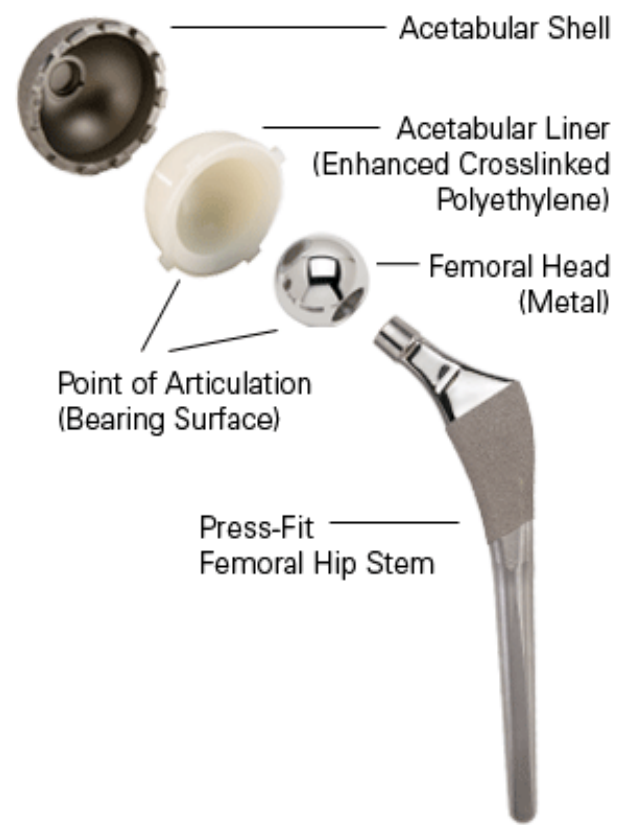

Gambar 1. Bagian-bagian utama sendi panggul buatan [1]

Masyarakat Indonesia yang mayoritas beragama Islam (sekitar 87,2 \%) maka dalam sehari melakukan lima kali aktivitas gerakan salat. Gerakan salat secara umum terbagi menjadi lima gerakan dasar, yaitu berdiri, ruku', sujud, duduk diantara dua sujud, dan takhiyat [3]. Bagi pasien penyandang sendi panggul buatan aktivitas gerakan salat tersebut akan mempengaruhi impact pada sendi panggul buatan yang disandangnya. Dalam penelitian ini simulasi dilakukan untuk mendapatkan persentase beban gaya reaksi yang terjadi pada tiap gerakan salat. Selain itu juga dengan simulasi dapat dilakukan perhitungan range of motion (ROM) untuk menentukan besar sudut yang terjadi pada setiap gerakan salat. Pada Sendi panggul memungkinkan pergerakan dari paha pada tiga arah dengan ROM yang luas. Paha dapat melakukan fleski hingga $120^{\circ}-125^{\circ}$ dan ekstensi hingga $10^{\circ}-15^{\circ}$ pada bidang sagital. Paha juga dapat melakukan abduksi hingga $30^{\circ}-45^{\circ}$ dan adduksi $15^{\circ}-30^{\circ}$. Sedangkan untuk rotasi, paha dapat melakukan internal rotasi hingga $30^{\circ}-$ $50^{\circ}$ dan eksternal rotasi [4].

Besar beban gaya reaksi atau ground reaction force (GRF) serta ROM digunakan sebagai data pembebanan pada sendi panggul buatan. Dengan menggunakan simulasi FEM maka didapatkan besar tegangan dan deformasi yang terjadi pada sendi panggul buatan saat gerakan salat. Dalam kaitannya tegangan dan deformasi secara umum kecenderungan nilai tegangan akan berbanding lurus dengan nilai deformasi yang terjadi [5].

Tujuan dari penelitian ini adalah untuk mengetahui besar tegangan serta deformasi yang terjadi pada sendi panggul buatan sehingga pasien artificial hip joint replacement dapat memiliki perhatian serta referensi dalam melakukan gerakan salat agar kondisi sendi panggul buatan dapat berfungsi dengan baik.

\section{Metodologi Penelitian}

Pengukuran GRF secara eksperimental pada penelitian ini dilakukan terhadap tiga orang dengan berat $70 \mathrm{~kg}, 73 \mathrm{~kg}$, $78 \mathrm{~kg}$. Proses pengukuran dilakukan dengan dengan menggunakan timbangan digital. Kemudian setelah pengukuran dilakukan analisis beban gaya reaksi dengan simulasi. Simulasi ini dilakukan dengan menggunakan pemodelan human body dengan lima macam gerakan pada salat, yaitu berdiri, ruku', sujud, duduk diantara dua sujud, dan takhiyat akhir seperti ditunjukkan pada Gambar 2. Pada tiap sendi anggota tubuh pemodelan ditambahkan ball joint agar pemodelan human body dapat diubah sesuai gerakan salat. Pembebanan yang dilakukan pada simulasi dengan Solidworks 4.0 adalah gravitasi sebesar $9,81 \mathrm{~m} / \mathrm{s}^{2}$ sehingga beban terdistribusi ke seluruh bagian tubuh. Berat badan tubuh yang digunakn pada pemodelan ini sebesar $80 \mathrm{~kg}$ serta tumpuan yang digunakan terletak pada anggota tubuh yang berkontak dengan bidang.

ROM yang terbentuk pada gerakan salat ditentukan berdasar pada pemodelan pada simulasi yang selanjutnya dibandingkan dengan hasil pengukuran yang telah dilakukan. Gambar 3 mengilutrasikan perhitungan ROM pada salah satu gerakan salat, yaitu sujud. Pada penelitian ini perhitungan ROM yang dilakukan menghasilkan sudut pada gerakan berdiri, ruku', sujud, duduk diantara dua sujud dan takhiyat masing-masing sebesar $0^{\circ}, 0^{\circ}, 107^{\circ}, 158^{\circ}$, dan $140^{\circ}$. Informasi mengenai sudut yang terbentuk dari tiap gerakan salat ini sangat diperlukan karena sudut tersebut akan mempengaruhi kondisi artificial hip joint serta letak femoral condyle dantibial pad. 


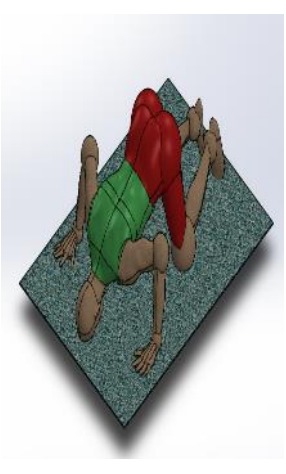

(a)

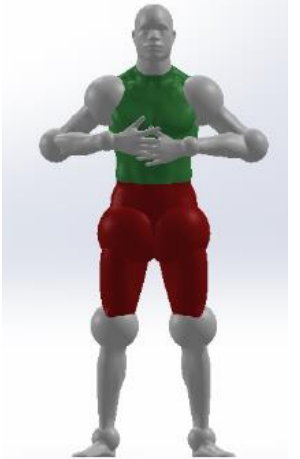

(b)

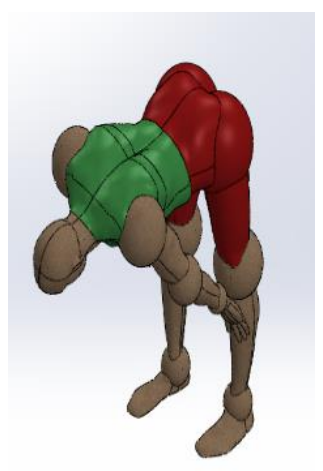

(c)

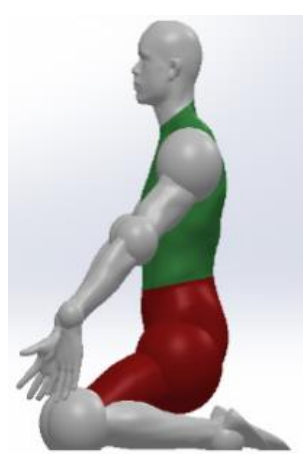

(d)

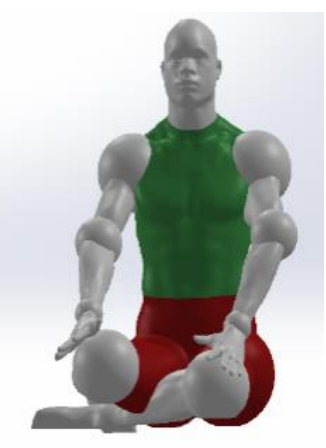

(e)

Gambar 2. Pemodelan human body (a) gerakan berdiri, (b) ruku', (c) sujud, (d) duduk diantara dua sujud, (e) takhiyat.

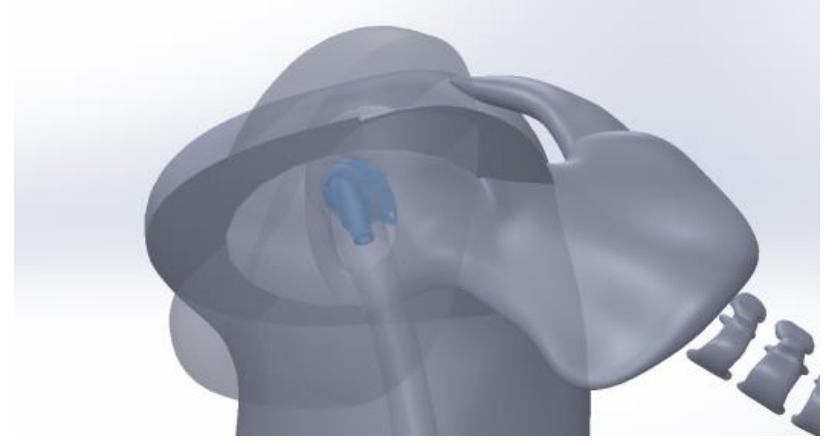

Gambar 3. Perhitungan ROM hip joint pada gerakan sujud

Selanjunya analisis tegangan von Misses serta deformasi yang terjadi dilakukan dengan menggunakan FEM. Dalam pemodelan menggunakan FEM ini terdapat empat komponen pada model sendi panggul buatan, yaitu: acetabular shell, acetabular liner outer, acetabular liner inner dan stem. Pada acetabular shell, acetabular liner outer dan steam head menggunakan material AISI 316L dengan Modulus Young sebesar1.93×105 MPa, Poisson Ratio sebesar 0,3 dan Yield Strength sebesar 137,9 MPa. Sedangkan pada tibial pad dan tibial plateu menggunakan material ultra-high molecular weight polyethelene (UHMWPE) dengan Modulus Young sebesar $893 \mathrm{MPa}$, Poisson Ratio sebesar 0,44 dan Yield Strength sebesar 23,56 MPa. Analisis dilakukan dengan mesimulasikan pemodelan sendi panggul buatan pada lima kondisi gerakan. Gambar 4 menunjukkan meshing pemodelan sendi panggul buatan pada salah satu kondisi salat, yaitu sujud.

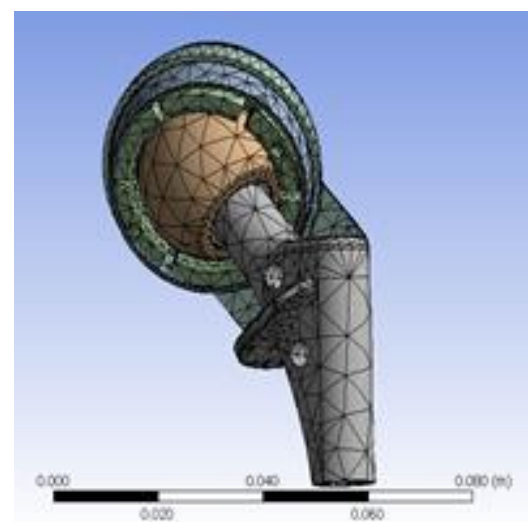

Gambar 4. Meshing pada pemodelan sendi panggulbuatan saat gerakan sujud.

\section{Hasil dan Pembahasan}

Tabel 1 menunjukkan perbandingan GRF gerakan salat yang diperoleh dari pengukuran dan simulasi. Dari tabel tersebut tampak bahwa GRF hasil simulasi memberikan hasil yang cukup akurat. Pada hasil perhitungan GRF ini tiap persentase gerakan yang dihasilkan akan mendapatkan nilai satu kali dari berat total. Untuk berdiri dan ruku' maka tinggal dikali dua untuk mendapat kan nilai GRF total dari tiap gerakan tersebut. Dari kelima gerakan tersebut maka berdasarkan harga GRF yang diperoleh dapat dipahami jika gerakan pada berdiri dan rukuk mempunyai persentase nilai tegangan yang paling tinggi diantara gerakan lainya. 
Tabel 1. Ground reaction force (GRF) gerakan salat.

\begin{tabular}{lcc}
\hline \multicolumn{1}{c}{ Gerakan } & GRF Pengukuran (BW) & GRF Simulasi (BW) \\
\hline 1.Berdiri & 0,500 & 0,501 \\
2. Ruku & 0,500 & 0,530 \\
3. Sujud & & 0,300 \\
a. Dahi & 0,29 & 0,06 \\
b. Tangan & 0,061 & 0,280 \\
c. Lutut & 0,289 & 0,120 \\
4. Duduk di antara dua sujud & & 0,191 \\
a. Lutut kanan & 0,124 & 0,663 \\
b. Ankle kanan & 0,190 & 0,060 \\
c. Kaki kiri & 0,663 & 0,233 \\
5. Tahiyat Akhir & & 0,767 \\
a. Lutut kanan & 0,061 & 0,233 \\
b. Ankle kanan & 0,767 & \\
c. Kaki kiri & & \\
\hline
\end{tabular}

Gambar 5 menunjukkan hasil analisis tegangan sendi panggul buatan pada lima gerakan salat menggunakan FEM. Sedangkan Tabel 2 menunjukkan tegangan von Misses pada sendi panggul buatan yang diperoleh melalui analisi FEM pada penelitian ini dibanding dengan hasil yang diperoleh pada Ref [5].

Tabel 2. Tegangan von Misses sendi panggul buatan pada gerakan salat.

\begin{tabular}{ccc}
\hline Gerakan & Simulasi (MPa) & Jurnal (MPa) [5] \\
\hline Berdiri & 32,15 & 27,60 \\
Ruku' & 32,46 & 19,90 \\
Sujud & 21,60 & 17,80 \\
Duduk Dua Sujud & & 8,70 \\
a)kaki kanan & 19,10 & 23,56 \\
b)kaki kiri & 9,30 & 26,36 \\
Takhiyat Akhir & & 21,70 \\
a)kaki kanan & 26 & \\
b)kaki kiri & &
\end{tabular}

Dari hasil tersebut tampak bahwa kecuali pada gerakan tahiyat akhir, hasil yang diperoleh pada penelitian ini memberikan hasil yang sedikit lebih besar. Dari Tabel 2 juga tampak bahwa tegangan terjadi ketika dalam gerakan posisi berdiri dan rukuk. Kondisi ini sesuai dengan hasil GRF yang telah diuraikan di atas.

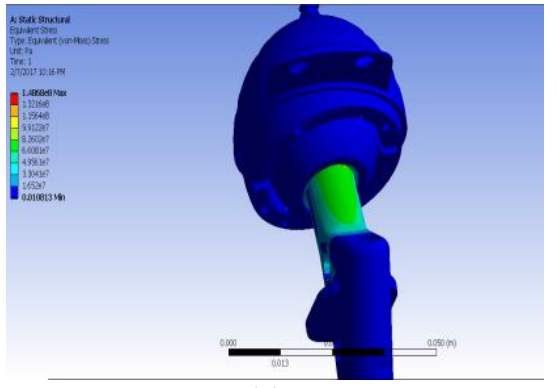

(a)

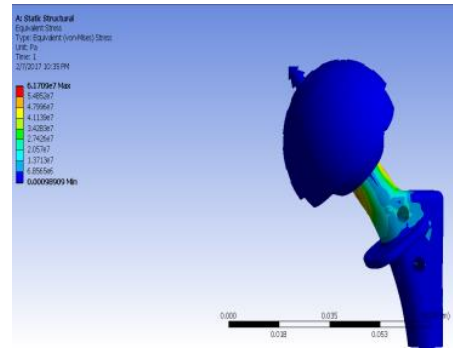

(b)

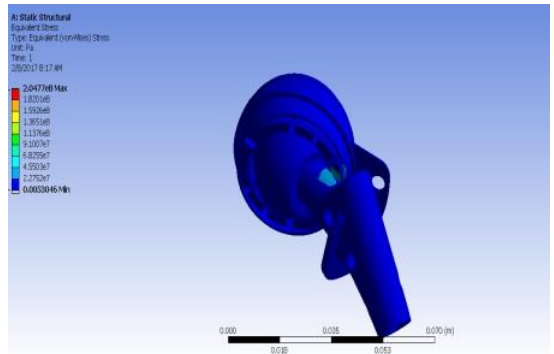

(c)

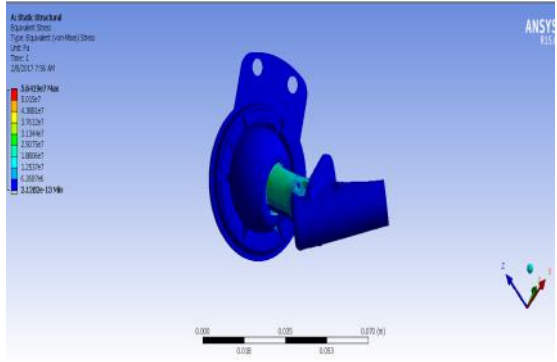

(d)

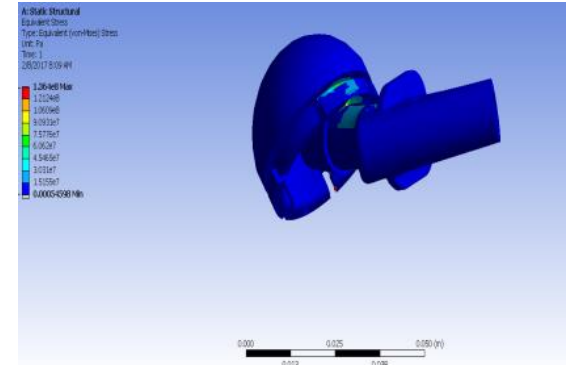

(e)

Gambar 5. Hasil simulasi tegangan sendi panggul buatan saat (a) berdiri, (b) rukuk, (c) sujud, (d) duduk diantara dua sujud, (e) takhiyat. 


\section{Kesimpulan}

Dari analisis perhitungan GRF menunjukkan bahwa gerakan sujud mempunyai nilai persentase berat tubuh yang besar dibandingkan gerakan lain yang mengalami kontak langsung antara sendi panggul dan bidang. Hasil dari perhitungan beban gaya reaksi tersebut kemudian digunakan sebagai pembebanan artificial hip joint serta memasukkan nilai range of motion (ROM) sebagai pemodelan dari sendi panggul buatan untuk gerakan salat berdiri, ruku', sujud, duduk diantara dua sujud, dan takhiyat akhir dimana besar sudut yang terbentuk adalah $0^{\circ}, 0^{\circ}, 107^{\circ}, 158^{\circ}$, dan $140^{\circ}$. Dari kelima gerakan tersebut, aktivitas gerakan sendi lutut yang berkontak dengan bidang adalah, sujud, duduk diantara duasujud, dan takhiyat.

Simulasi yang dilakukan menempatkan titik pembebanan dan tumpuan (fixed) yang sama pada tiap gerakan pemodelan artificial hip joint, dimana pembebanan diletakkan pada femoral condyle dan tumpun (fixed) terletak pada bagian tibial plateu. Dari Besar tegangan yang terjadi pada gerakan salat baik saat berdiri, ruku', sujud, duduk diantara dua sujud, dan takhiyat akhir adalah 32,15 MPa ; 32,46 MPa ; 21,6 MPa ; 19,1 MPa untuk kaki kanan dan 9,3 MPa untuk kaki kiri ; 21,7 MPa untuk kaki kanan dan $26 \mathrm{MPa}$ untuk kaki kiri. Dari simulasi maka didapatkan nilai tegangan terbesar terdapat pada gerakan berdiri dan rukuk yaitu sebesar $32,15 \mathrm{MPa}$ dan $32,46 \mathrm{MPa}$ dan tegangan terkecil pada gerakan duduk diantara dua sujud kaki kiri. Hal tersebut dapat terjadi karena pada gerakan sujud merupakan gerakan dimana sendi panggul berkontak langsung dengan bidang dan mendapatkan nilai pembebanan gaya reaksi yang paling besar dibandingkan gerakan duduk diantara dua sujud dan takhiyat meskipun pada range of motion (ROM) sudut paling besar yang terbentuk pada artificial hip joint adalah pada gerakan duduk diantara dua sujud.

Hasil analisis tersebut memberikan informasi kepada pasien artificial hip joint replacement untuk berhati-hati dan cermat dalam melakukan gerakan salat pada saat sujud karena gerakan tersebut memiliki distribusi tegangan serta nilai deformasi yang paling tinggi sehingga bila dalam melakukan gerakan tersebut kurang berhati-hati maka dapat mempengaruhi kerja serta fungsi dari sendi lutut buatan.

\section{Referensi}

[1] Exactech, Components of a Hip Replacement, http: http://exactech.co.jp/patients-caregivers/joint-replacementsurgery/hip-replacement/components-hip-replacement

[2] Narayan, R., 2009, Biomedical Materials. Springer Science + Business Media LCC.

[3] Al-Bani, M.H., 2103, Ringkasan Sifat Sholat Nabi SAW. Available at: www.ibnumajjah.com.

[4] Hamill, J., Knutzen, K.M., 2009, Biomechanical Basis of Human Movement. Lippincot Williams \&Wilkins China

[5] Kluess, D., Martin, H., Mittelmeier, W., Schmitz, K.P., Bader, R., 2007, Influence of Femoral Head Size on Impingement, Dislocation and Stress Distribution in Total Hip Replacement, Medical engineering \& physics, 29(4), pp. 465-471

[6] Kiefer, H., 2007, Current Trends in Total Hip Arthroplasty in Europe and Experiences with the Bicontact Hip System, Treatment of Osteoarthritic Change in the Hip, pp. 205-210. Springer Japan.

[7] Ismail, R., Saputra, E., Dhaneswara, Y.A.A., Haris, A., Umardani, Y., Anwar , I.B., Jamari, J., 2015, Analisis Metode Elemen Hingga Pada Sendi Panggul Buatan Saat Digunakan Untuk Menjalankan Ibadah Salat, Universitas Diponegoro. 